\title{
Special educators' perceptions of their role in inclusive education: A case study in Finland
}

\author{
Christopher Mihajlovic \\ Johann-Peter-Schäfer Schule, Germany
}

\begin{abstract}
Qualitative research methods were used to conduct case studies in three public schools in Finland to explore the changing role of the special education profession in Finland after the legislative reform in 2011 regarding educational support. With the implementation of the three tiered-support system, the special educator has become a profession with versatile tasks. This paper investigates mainly the participants' points of view regarding the work structure and pedagogical settings within their schools, as well as challenges and positive aspects related to their work. Semi-structured interviews and participant observation were used as data collection tools. Four special educators in mainstream schools located in Southern Finland participated in the research undertaking. Given this small sample group, the results of the study make no claims for generalisability but the findings revealed that the work of special educators mainly consists of teaching and background work, depending on their operational area. Although the consultative role exists, the findings showed that it has not yet become a regular part of the work for most special educators. The focus of their work lies on the support for students with different learning needs in the classroom.
\end{abstract}

Keywords: Inclusive education; Special education; Special education teachers; Disability; Finnish school system

Article History: Submitted 25 March 2020; Revised 9 May 2020; Published online 10 May 2020

\section{Introduction}

With the adoption of the Salamanca Statement in 1994, inclusion has become a very important topic on the political agenda in Europe. Internationally, there has been an ongoing debate on inclusion and the perspectives vary among different disciplines. The concept of inclusion is often linked to discourses of special education that aimed at regarding the segregation of students with disabilities into special schools as normal (Vislie, 2003). In Finland, normalisation was a strong statement in launching the comprehensive school in 1972. Normalisation theory arose in the early 1970 s and it is one of the strongest and long-lasting integration theories for people with disabilities.

In 1998, the new Finnish 'Basic Education Act' focused on equal rights to education for all, no matter of the school or municipality (Ekstam, Linnanmäki, \& Aunio, 2015).

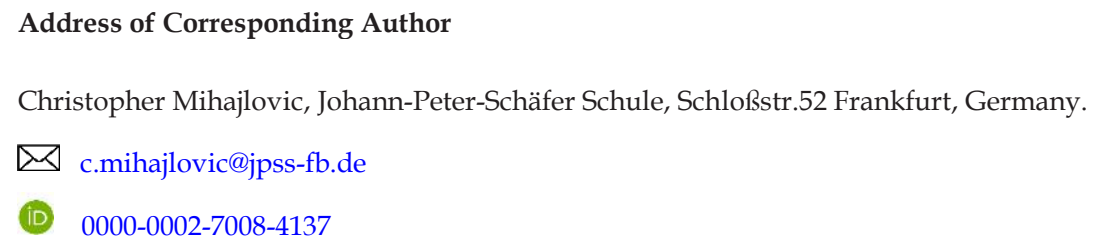

How to cite: Mihajlovic, C. (2020). Special educators' perceptions of their role in inclusive education: A case study in Finland. Journal of Pedagogical Research, 4(2), 83-97. 
The United Nation policies (United Nations, 2006) build upon a broad understanding of inclusion, capturing any group of students and as a way of responding to diversity among learners and is thus not limited solely on children with disabilities. In Finland, however, inclusive education has been generally regarded more as a pedagogical than an ideological question and it usually refers only to educating students with special educational needs in mainstream settings (Malinen, Väisänen \& Savolainen, 2012).

Internationally, the current trend is to educate more pupils with special needs in general education classroom settings which has strengthened the position of support services, such as special educators. Due to reforms of the special educational support system in 2011 and the expansion of the inclusive education movement, the special education profession in Finland has undergone many changes (Ström \& Hannus-Gullmets, 2015). In addition to the traditional role as an expert in learning difficulties, the work profile of special educators has nowadays become more versatile and includes collaborative and consultative practices. According to research conducted by Dingle, Falvey, Givner \& Haager (2004) from the perspective of general educators, special educators are expected to possess knowledge of common characteristics of different disabilities, expertise of principles and techniques of behaviour modification, developing individual educational plans (IEPs), and collaborative and consultative activities (such as co-planning and coteaching). In Finnish mainstream education, however, the special educators often work alone (Takala, Pirttimaa, \& Törmänen, 2009).

Previous research demonstrates that Finnish student teachers and in-service teachers are more sceptical towards the implementation of inclusion-based practices in comparison to teachers in other countries: A comparative analysis by Savolainen, Engelbrecht, Nel \& Malinen (2012) of primary and secondary education teacher's self-efficacy in implementing inclusive practices in South Africa and Finland indicated that Finnish teachers had many concerns about inclusive practices, such as collaboration with other professionals. A recent study conducted by Takala, Wickman, Uusitalo-Malmivaara, \& Lundström (2015) also revealed, that Swedish student teachers have a more positive attitude towards inclusion and inclusive practices than their Finnish counterparts. Inclusive practices seem to play only a minor role in Finnish special teacher education compared to Norway (Hausstätter \& Takala, 2008).

After the Finnish legislative reform, several studies (mostly quantitative) have been conducted regarding the Finnish special education teachers' role and the special education practice (Björn, Aaro, Koponen \& Fuchs, 2016; Pirttimaa, Kokko, Räty, Pesonen, \& Ojala, 2015; Sirkko, Wickmann \& Takala, 2018; Saloviita, 2018; Takala \& Head, 2017). According to most studies, teacher collaboration and the use of co-teaching has increased in Finnish-speaking schools in Finland since the reform. A recently conducted quantitative study by Sundqvist, Björk-Åman \& Ström (2019) concerning special educators' roles in Swedish-speaking schools in Finland revealed, however, that most special educators use their time teaching pupils in segregated educational settings such as small-groups, and collaborative practices such as co-teaching is still not very common.

Moreover, research on the work of special educators in Finnish primary and secondary schools found a lack of defined work roles (Takala et al., 2009). Before new amendments regarding special education were made to the Finnish Basic Education Act (642/2010), the work of the special educators consisted mainly of three elements: teaching, consulting and background work (Takala et al., 2009). The main problems experienced by the teachers in this study were the lack of time for consultation and co-operation, an unclear work profile and too much work. Harper (2017) also revealed a lack of time to plan lessons in conjunction with the class teacher or subject teacher. A lack of adequate time seems to be a factor affecting success within inclusive classrooms and is of special interest within this research.

Little has been investigated on a qualitative basis how special education teachers see their professional role and their work profile and how it differs within different school contexts. A qualitative study conducted by Bettini, Wang, Cumming, Kimerling \& Schutz (2019) explored how four special educators in 'self-contained' classes for students with emotional and behavioural 
disorders defined and experienced their roles. The study participants in this research experienced dissonance between their ideal roles and their actual daily work (such as extra responsibilities). The purpose of the present study was selected because of the gap in qualitative literature compared to quantitative studies in this field (Sundqvist, Björk-Åman \& Ström, 2019; Takala et al., 2009).

In order to fill this research gap, the main aim of this paper is to identify the variety of roles and tasks that are given to special educators from their own point of view. This study offers deep insights into the perspectives of four special educators about their responsibilities and pedagogical support for students with special needs at a practical level. Given this small sample group, the present study makes no claims for generalisability, but the findings could help to understand the perspectives of (Finnish) special educators towards their professional role and could justify the need for a more effective cooperation between special educators and general education teachers in Finland and elsewhere.

First, the paper gives a short overview about the provision and model of special support in Finland. The author then describes the research design and procedure, data collection and analysis. Results will be presented and discussed through the categories (1) Structure and main responsibilities of work (2) Organization of pedagogical support on school level, and (3) barriers and challenges in their pedagogical practice.

\subsection{Model of Support}

Before the Basic Education Act (Law 642/2010) went into effect in 2011, there were two forms of educational support in Finland: general and special support (part-time and full-time special education). A legislative reform regarding educational support was also adopted in 2011, as the number of students in full-time special education was steadily increasing between 2001 and 2009 from 5\% to $8 \%$ (Ekstam et al., 2015). Moreover, it seemed that municipalities were using different inclusion criteria for special education, which resulted in inequalities in provision. Consequently, reforms of the special education system were made: The reform instituted a three-tier support model called 'Learning and Schooling Support', which consists of general, intensified and special support (Finnish National Board of Education, 2016; Pulkkinen \& Jahnukainen, 2016).

The tier system is as follows: [1] General support is for all students and is a part of everyday teaching. It includes many forms of support such as co-operation between all teachers, and between teachers and parents. If this support is not sufficient, tier [2] (intensified support) is given to the student for a certain time. The decision of intensified support is based on a pedagogical assessment made by teachers and includes an individual learning plan. Intensified support includes many forms of systematic support such part-time special needs education and individual guidance.

If the student does not perform as expected, it will then be determined whether the child should receive the strongest support form [3] (special support), which is reported in a pedagogical statement document (Ekstam et al., 2015). The teachers and the school's student welfare group are responsible for developing a pedagogical statement document, considering whether the student will receive special support which also requires an IEP. Special support usually includes different types of pedagogical arrangements in order to support the student.

While general support for children in Finland is quite common (about $30 \%$ of all learners receive general support), intensified support was received by $10,6 \%$ and special support by $8,1 \%$ of comprehensive school pupils in autumn 2018 (see Figure 1; OSF, 2019a).

The Finnish model of support resembles the response to intervention (RTI) model, that has been introduced in the early 2000s as a framework for identifying students with learning disabilities in the United States (Björn et al., 2016). The current models in both countries aim at diminishing the number of students with special support, and at the same time decrease the rising costs of special education funding (Jahnukainen \& Itkonen, 2015). However, there are several differences between 


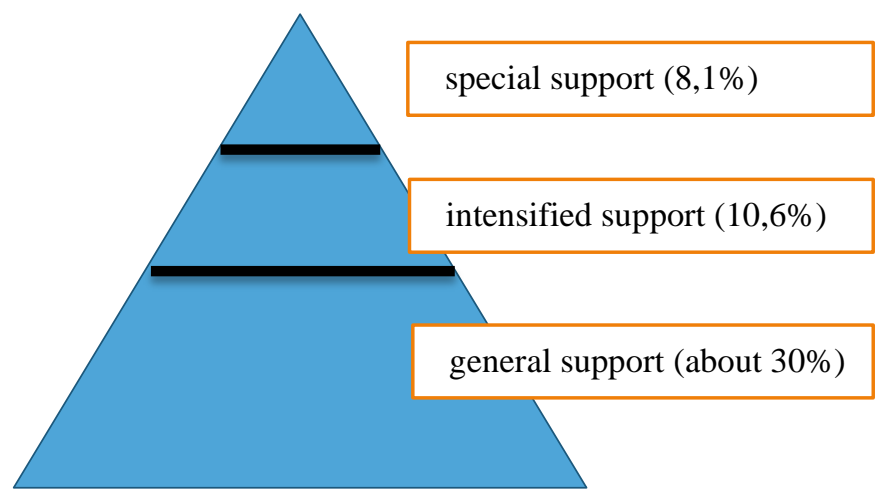

Figure 1. Share of comprehensive school pupils having received general, intensified or special support among all comprehensive school pupils in 2018 (OSF, 2019a)

the RTI framework and the Finnish model. One important difference lies in the fact, that the RTI model was primarily developed in the U.S. in order to identify learning difficulties and delivering evidence-based instruction. The Finnish model on the other hand, was introduced to re-structure the existing support service model for struggling students (Björn et al., 2016; Jahnukainen \& Itkonen, 2015).

\subsection{Provision of special support in Finland}

According to 'Official Statistics of Finland' (OSF, 2019b) 91\% of all students with special support go to mainstream schools in Finland, either in general education groups or in special groups within the comprehensive school. Only $9 \%$ of all students with special support are taught in special schools. It is obvious, however, that physical integration does not automatically mean functional integration. According to OSF (2019b) approximately $21 \%$ of all students with special support are taught fully in a general education class. The most common option $(43 \%)$ is partial teaching in general education groups and special classes located in mainstream schools. $27 \%$ of all students with special support are taught full-time in special classes in mainstream schools (see figure 2).

These findings concur with previous studies on inclusive teaching of students with severe intellectual disabilities, which confirm that individual integration of students with special support into the full-time mainstream classroom occur only seldom (Jahnukainen \& Korhonen 2003, Pirttimaa et al. 2015).

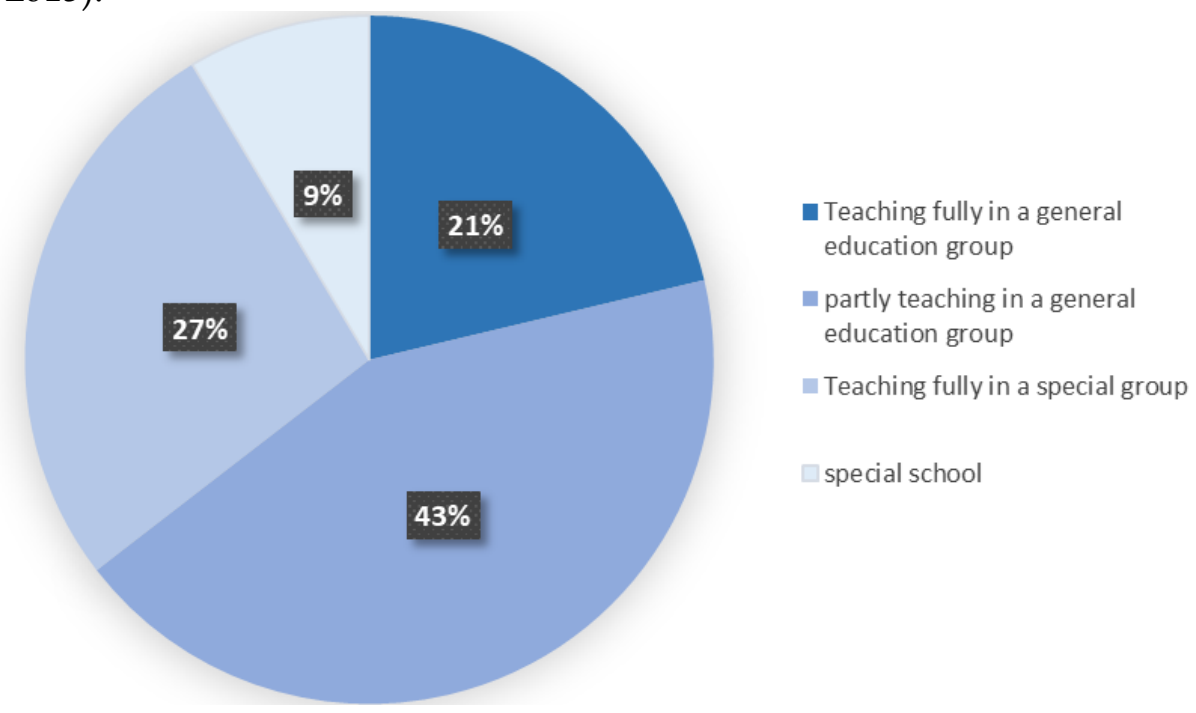

Figure 2. Comprehensive school pupils having received special support by place of provision of teaching, 2018 (OSF, 2019b). 
In Finland, special educators are traditionally responsible for teaching children with learning difficulties. The work profile of Finnish special educators has nowadays become more versatile, and depends on the operational area and the professional background. According to previous research in this field (Ström \& Hannus- Gullmets, 2015), the profession of the special educator in Finland is still divided into two professions: The special class teacher and the special teacher professions. Although the concept of the special class teacher is not mentioned in official documents such as the Basic Education Act and the national core curriculum (Finnish National Board of Education, 2016), both professions still exist in reality (Ström \& Hannus- Gullmets, 2015). The Basic Education Decree, however, mentions two differing types of qualifications depending on the level of support: Teachers providing special support need to have a double qualification (class teacher and special teacher) while a special teacher qualification is sufficient for the other support levels (Ström \& Hannus- Gullmets, 2015). Special class teachers traditionally work in more segregated settings such as special schools or (full-time) special classes within regular schools. The study conducted by Takala et al. (2009) also indicates that special class teachers work mainly with small groups of children and more seldom in inclusive settings in co-operation with another teacher. Special teachers, on the other hand, are more often involved in part-time special education settings and co-teaching with general educators. As inclusive practices are becoming more common, the special class teacher is "deconstructed" on policy level but is still exists on municipality level (Ström \& Hannus- Gullmets, 2015).

In conclusion, it can be said that the amount of pupils receiving special support in a general education group (fully or partly) has increased while teaching fully in a special group or special school has decreased in recent years (OSF, 2019b). Besides, collaboration between general and special educators have become more important with the implementation of the three-tier support model (Saloviita, 2018; Takala \& Head, 2017). The present study therefore aims at providing insight into the exploration of special educators' roles under the new model of educational support at a practical level.

\section{Method}

\subsection{Description of the Study}

The present study tries to find out, how the participants perceive their own role within different institutional and school-organisational conditions. The case study data reported in this paper were collected within the context of a larger research project. The conceptual framework for the research was derived from existing literature.

There is a great diversity among the schools of this study, which has an impact on the provision of special support and the operational area of the study participants. As previous research could show, the educational profile (Carrington \& Elkins, 2002; Magnússon, Göransson \& Nilholm, 2014), the model of support (Carrington \& Elkins, 2002), and teachers' ideals and knowledge (Carrington, 1999) impacts on the everyday practice of (inclusive) schools. Overall, three comprehensive schools in the Helsinki area participated in the present study (See Table 1).

School A and B place their pupils with special needs partly in mainstream classrooms with additional support by a special educator, and sometimes in semi-segregated settings. These schools have established a flexible provision, so that children identified as having special needs spend their time in different learning environments, that is tailored to the needs of each individual child (Ainscow, Dyson \& Weiner, 2013). The teachers in these schools (teacher 1, 2 and 3), however, still use most of their time teaching pupils in educational settings that are more or less segregated, such as individual or small-group teaching (Sundqvist, Björk-Åman \& Ström, 2019).

School C places children with special educational needs mainly in 'resource rooms', so that they spend most of the time away from their peers. A special class teacher (teacher 4 ) is responsible for teaching those pupils almost full-time in a special group. 


\subsection{Research Design and Data Collection}

The investigation consists of a qualitative approach. Qualitative data were collected through semistructured interviews and participant observation (Lüders, 2009; Mayring 2010). The study was guided by the following questions: What are special educators' perceptions of their roles and main responsibilities in their work? How is their pedagogical support organized on school level and what are possible challenges?

The research questions were formulated based on the literature review described in the introduction of this paper (Ström \& Hannus- Gullmets, 2015; Takala et al., 2009). The study used an inductive approach in analysing interview data to reveal similarities and differences between the schools regarding inclusive practices and the role of the special education teacher.

\subsubsection{Sampling method and description of study participants}

A purposeful sampling approach using the strategy of criterion sampling was used to recruit the participants (Patton, 2002). Participants were four special educators (all female) who met the key requirement of working in mainstream schools for at least seven years so it was assumed that the participants possess sufficient experience with the phenomenon of interest (the change of their profession due to the legislative reform in 2011). As a language barrier existed between the researcher (from Germany) and the participants of the study, interviews were conducted in English, which is not the native language for participants and researcher. The researcher was not familiar with the local language (Finnish). Consequently, participants were also chosen based on their language proficiency in English.

All participants had a pedagogical diploma in special needs education, whereas three had a double qualification (class teacher and special teacher education). Their ages ranged from 36 to 60 , and their pedagogical work experience ranged from 8 to 30 years.

Participants were provided with information letters about the research project and signed consent was obtained prior to the beginning of the research. Participation was voluntary and withdrawal at any stage was possible. Data collection took place in three public comprehensive schools (grades 1-9) and one special school in Southern Finland. The participants had different professional backgrounds in the field of special education due to their teacher training, work experience and their operational area. A brief description of the five participants, using pseudonyms, is presented in Table 1.

Table 1.

Description of Participants $(n=4)$

\begin{tabular}{|c|c|c|c|c|c|}
\hline Pseudonym & Gender & Age & School, class level & $\begin{array}{l}\text { Teaching } \\
\text { experience }\end{array}$ & Description \\
\hline Teacher 1 & Female & 36 years & $\begin{array}{c}\text { Comprehensive school, } \\
\text { grades 1-6 (School A) }\end{array}$ & 8 years & special teacher \\
\hline Teacher 2 & Female & 44 years & $\begin{array}{l}\text { Comprehensive school, } \\
\text { grades 1-9 (School A) }\end{array}$ & 13 years & special teacher \\
\hline Teacher 3 & Female & 41 years & $\begin{array}{l}\text { Comprehensive school, } \\
\text { grades 1-9 (School B) }\end{array}$ & 11 years & special teacher \\
\hline Teacher 4 & Female & 60 years & $\begin{array}{l}\text { Comprehensive school, } \\
\text { grades 1-9 (School C) }\end{array}$ & 30 years & $\begin{array}{l}\text { special class } \\
\text { teacher }\end{array}$ \\
\hline
\end{tabular}

\subsubsection{Interviews}

The interview questions were designed so that the teachers could freely describe the aspects they consider important in their work. All interviews were conducted by the author in a quiet room to ensure participants felt comfortable and to avoid possible interruptions. The teachers were encouraged to explain their answers and share their experiences via follow-up questions. The interviews lasted 40 minutes on average and were recorded and transcribed verbatim. 


\subsubsection{Participant observation}

In addition, participant observation was conducted to expand data gathered from the semistructured interviews. Participants were observed teaching to special classes which included students with different disabilities. A guideline with predetermined categories (Lüders, 2009) was used, to conduct the observations in a more structured manner. The categories focused on the activities of the special education teachers during the lessons and their interaction with pupils and forms of co-operations between the teachers. In addition, the observations focused on the variety in pupils' participation and non-participation and relations between pupils and the teaching staff (Munk \& Agergaard, 2015). Additionally, informal observations and interactions with staff and students in different situations (classroom, school breaks) across the school environment allowed a better understanding of the school setting (Carrington \& Elkins, 2002).

\subsection{Data Analysis}

The interviews were analysed by adopting the inductive content analysis method (Mayring, 2010). The main principle of inductive category development is that the categories are as near as possible to the material, the material is worked through, and categories are tentative and deduced step-bystep. The analysis consisted of two different phases: In the first phase, the author read the interviews through several times in order to understand the "big picture". The second phase focused on discovering responses that highlight important messages or findings using inductive content analysis in which the qualitative data were analysed without theoretical assumptions (Mayring, 2010). This method was used to explore the similarities and differences regarding the teacher's work profiles and possible barriers and challenges in their pedagogical practice.

The analysis involved three steps: data reduction, grouping and conceptualisation (Flick, 2009). First, a criterion of definition has been formulated, derived from the theoretical background and the research question. The category definition determined the aspects of the textual material taken into account. Following the main research question, the first category definition was related to the perceptions of the roles and main responsibilities of the participants. All text segments that referred to the teacher's roles, responsibilities and perceived teaching competence were identified and coded into the same category. In the second step (grouping) the selected descriptions were step by step subsumed in different groups. Following the research questions, these groups were conceptualised as categories, which were carefully established and revised within the process of analysis (step 3: conceptualisation). After $50 \%$ of the material was worked through, categories were revised and checked in respect to their reliability. Within this process main categories and sub-categories emerged throughout data analysis (See Table 2.). The broad categories that emerged from the data analysis are: 1) Structure and main responsibilities of work (2) Organization of pedagogical support on school level, and (3) barriers and challenges in their pedagogical practice.

Table 2.

The main categories and sub-categories obtained from the content analysis

\section{Main categories Sub-categories}

\begin{tabular}{lll}
\hline $\begin{array}{l}\text { Structure and main } \\
\text { responsibilities of work }\end{array}$ & - Individual teaching / teaching a small group \\
& - Cooperating with teachers and multi-professional group \\
\hline $\begin{array}{l}\text { Organization of pedagogical } \\
\text { support on school level }\end{array}$ & - Creating supportive learning environments in segregated \\
& - $\begin{array}{l}\text { placements (part-time and full-time special education) } \\
\end{array}$ & educational needs (in a general education group) \\
\hline $\begin{array}{l}\text { Barriers and challenges in their } \\
\text { pedagogical practice }\end{array}$ & - Lack of resources (time, missing teaching assistants) \\
& - Type and severity of students' disabilities \\
& - General education) teachers' attitudes \\
\hline
\end{tabular}




\subsection{Trustworthiness}

The trustworthiness of this study was achieved in various ways. Credibility was accomplished by triangulating the data between the types of data collection (semi-structured interviews, observation of lessons, informal observations). Member reflections have been used to examine whether the participants find the research comprehendible and provided additional data for deeper analyses. The interview transcripts have been e-mailed to the participants after each interview, which ensured trustworthiness of the data (Meho, 2006).

In addition, several PhD colleagues who had expertise in qualitative research agreed to serve as peer debriefer. Peer debriefing contributed to the trustworthiness of the study. Through peer debriefing, the researcher explored the research design and data analysis while colleagues, serving as critical friends, encouraged the researcher to investigate the research process from multiple perspectives (Figg et al., 2010).

This process led to a double analysis: Interview transcripts and participant-observation protocols were analysed from the perspective of the author and researcher regarding the questions that guided the research, as well as from the perspective of the colleagues, who questioned interpretations and methodological concerns. Differences in the process of analyzing the qualitative data were discussed, and changes were made until consensus was reached. The comprehension and interpretation of the interview data is challenging in cross-cultural research. Combining explicit and tacit forms of knowledge was important in order to understand the participants' opinions and attitudes. Gaining tacit knowledge takes significant time in the field. The longer researchers are present, the more likely they are able to understand culture's values (Tracy, 2010).

Data collection took place during a one-year stay as a visiting doctoral student and researcher in Finland and a considerable time was spent at each school (overall six months) so that trust was built with the participants.

\section{Findings and Comments}

\subsection{Structure and Main Responsibilities of Work}

As the schools organise their provision of special support in different ways, mostly depending on their student populations, the special educators' work structure and responsibilities vary a lot. According to my teaching observations, special education in all schools is conducted in small groups, individual and co-operational settings. The primary setting, however, is in small groups within the mainstream classroom or in separate settings for special instruction.

The results concur with previous findings (Sundqvist, Björk-Åman \& Ström, 2019; Takala et al. 2009) that the special teachers' direct work with the children mainly consists of individual teaching, teaching a small group and teaching children in co-operation with the class or subject teacher in the mainstream classroom. The participants indicated that they mainly teach small groups of children, and seldom work in co-operational settings. Some of them also emphasise the prevalence of separate groups for children with special educational needs, such as teacher 4 :

"In comprehensive school I usually teach a small group of children. So the special education classes are separated from the others, in the group there are about 7-10 students." (teacher 4)

The indirect work (mainly with adults) of the participants mainly consists of consulting and cooperating with other teachers, cooperation with parents, cooperation with the child's welfareteam and writing documents (such as the IEPs). Some teachers stressed collaboration with colleagues more than others did, but most of them defined individual students as the main target of their work in a separate group. Teacher 2, who teaches as a special teacher mainly in part-time special education, mentions the time spent on cooperating with class teachers and "paperwork":

"So I think quite often it is the case that the class teachers just need this support. They don't actually want any answers. We just want to talk about the problems or whatever and come up with the best 
solutions. And I think that I spend a lot of my time on filling out papers with the class teachers or just by myself" (teacher 2)

Teacher 2 mentions tasks that lie beyond teaching students: cooperating with class teachers and "background work" (Takala et al., 2009).

Although the consultative role exists, the results show that it has not yet become a regular part of the work profile for most participants. The focus of their work lies mainly on the support for students with different learning needs in the classroom and separate settings for special instruction.

\subsection{Organization of Pedagogical Support on School Level}

Some participants (Teacher 1,2,4) justify the prevalence of special education groups for children with special support as these solutions provide a learning environment that is tailored to the needs of such children. Teacher 1 articulated sentiments closely mirroring those of the majority of the participants, stating:

"If we could just have the freedom and possibilities to sit down and try to find out what is best for the child and not everyone goes to the big classrooms. This is too far. Inclusion is too far because there are some students (...) they do not make it in a big class. So we should have that option of small classes as well." (teacher 1)

The most common reasons for attending special education classes were difficulties in reading and writing, challenges in mathematics and behavioural issues. These classes could be seen as inclusive from the point of view of the participants themselves in that they try to provide an environment in which the pupils can function (Malmqvist \& Nilholm, 2016). However, the prevalence of these educational solutions is in contrast to what is meant by inclusion in the Salamanca statement (UNESCO, 1994), as children with special needs are segregated from other children.

Teacher 5 also refers to importance of supportive learning environments for children with special needs in separate groups, commenting:

"I cannot see how my student would benefit in inclusive classes. I believe that, whatever happens, there will always be the possibility for students like my students, to go to school in a peaceful environment." (teacher 4)

The general educator's lack of responsibility for individual learners' needs is evident in a quote from teacher 4, who claims that "class teacher and subject teacher don't receive the same education like us. They don't need to deal with children with disabilities because they are not supposed to do that. They are educated to teach children with normal standards". In this case, the regular class teachers are not encouraged to modify their teaching to cater for individual differences in the classroom (Carrington \& Elkins, 2002). Teacher 2 refers to the impact of her biographical background on choosing the specific profession as a special educator and the commitment to teaching children with special educational needs (within the mainstream classroom):

"Actually, I was 20 years old when I applied for special education studies. I had some experiences in this field because my mother is a special education teacher. It has been part of my daily life in our family. I have always been interested in students that don't learn like the rest of us." (teacher 2)

As the comments show, the majority of the participants are strongly values-driven. Their commitment, however, is not so much to inclusion itself, as to the principle of "doing the best they can" for their students with special educational needs (Ainscow, et al., 2013). More precisely, the special class teachers report significant practical difficulties in educating a wide range of students in the same classroom (Ainscow et al., 2013). Consequently, most participants are committed to educate 'their' students in particular settings, mostly in segregated placements.

The division between part-time special education and full-time special education taking place in schools is also reflected by the two professions within special education (Ström \& Hannus- 
Gullmets, 2015): The work of special teachers working in part-time special education is becoming more and more versatile, including tasks that reach beyond teaching students who face difficulties in learning. Those teacher who work as special class teacher (mainly in full-time special education) were more sceptical towards teaching children with special support in mainstream classrooms. They see teaching as their main task and regard it as necessary to have small classes in order to deal with the individual needs of the children.

\subsection{Barriers and Challenges in their Pedagogical Practice}

\subsubsection{Type and severity of students' disabilities}

Pupils with 'behaviour difficulties' are often regarded as being difficult to include in mainstream schools and classrooms (Ainscow et al., 2013). Teacher 4, for instance, shows negative attitudes toward the inclusion of children with mental disorders:

"Let's say that my child has some little learning problems or something such as a visual impairment, and no psychological problems. Of course, he or she should have the opportunity to go the same class with his mates. (...) But there will always be students who just can't cope in a big group. And that is my opinion about inclusion" (Teacher 4).

\subsection{2. (General education) teachers' attitudes}

According to previous research, co-operation and professional support for teachers has positive effects such as raising the quality of the teachers' work, weakening work-related stress and promoting joy both for the teachers and their pupils (Sirkko, Takala \& Wickman, 2018; Wolgast \& Fischer, 2017). Although, cooperative teaching was not a daily practice in the three comprehensive schools presented in this study, it was generally welcomed by the majority of the participants. Teacher 1, for instance, stresses the importance of cooperating in multi-professional teams and the role of their different perspectives in inclusive settings:

"One thing that is very important in supporting this inclusion is the cooperation between different professionals. For example, teachers and social workers and this psychiatric care. When we really work together then it is very supportive for inclusion. I think that this is a very important part of it. Because teacher look in one way, and psychiatric doctors and nurses have a different point of view. And when we put all the wisdom together then something can happen actually." (teacher 1)

Several participants (teacher 1,3,4), however, described difficulties regarding the collaboration with class and subject teachers. Teacher 3 , for instance, refers to the challenge of co-teaching to traditional conceptions of teaching and learning in daily practice:

"Co-teaching is difficult in real life. I think it is because the teachers are used to work in certain ways. And it is just not so easy to change." (teacher 3 )

This quotation reveals that some teachers seem to prefer to work alone rather than with other colleagues which also includes planning the lessons alone. Collaborative practices such as coteaching therefore needs further development in the inclusive classroom as suggested by Sirkko et al. (2018).

\subsubsection{Lack of resources}

While most of the participants regard the teachers' attitudes as main challenges in a possible cooperation, teacher 1 also mentioned a lack of resources (e.g. lack of time for planning and collaboration, missing teaching assistants) as an obstacle in inclusive teaching settings:

"Well, teachers' attitudes are the biggest challenge. But it is changing. The supportive things are, for example, teaching assistants are cut down. This is not a good thing." (teacher 1)

The following comment by teacher 2 concurs with the findings of Pirttimaa et al. (2015) where some special teachers see themselves as mediators between teachers and students regarding behavioural difficulties: 
"Sometimes teachers have problems with some students and when you send these students to another classroom, somehow the problems are becoming smaller. Usually they don't disappear but the problems become smaller." (teacher 2)

Segregating methods such as sending children to separate settings for special instruction seem to be a helpful strategy for most participants in order to avoid conflicts between general educators and children with behavioural issues.

For teacher 1, the cooperation with the child's family seems to be more profitable than the cooperation with her colleagues:

"But I think that the teachers are the most difficult people in this situation. The family is usually very cooperative because (...) they are willing to do everything because it is about their kid. But the teachers (.) sometimes they are not so easy." (teacher 1)

This comment reveals that class and subject teachers were not considered to be very willing to cooperate with special educators and other professionals. Sirkko et al. (2018) refer to a 'lone-wolf' spirit in Finnish schools and internationally, a culture of working alone which also includes planning instruction and evaluating results alone. Co-operation and co-teaching seem to play only a minor role in the teacher's daily practice. This is in contrast to the suggested operational area in professional recommendations and policy documents emphasizing the responsibility of all teachers (including class and subject teachers), to provide support for pupils with special needs (Alridge, 2008; Finnish National Board of Education, 2016).

\section{Discussion and Conclusion}

This paper investigated four special educators' points of view regarding their main responsibilities and challenges in their work. The study was guided by the following questions: What are special educators' perceptions of their roles and main responsibilities in their work? How is their pedagogical support organized on school level and what are possible challenges?

The participants had quite different experiences in the field of special education due to their work experience and their operational area. The results, however, are mainly in line with previous research (Sundqvist, Björk-Åman \& Ström, 2019; Takala et al, 2009). In relation to the first research question that guided the research, the main responsibilities of the special class teachers included individual and group support to students with learning difficulties and behavioural problems. Categories discovered in the analysis of this study align with results of the study conducted by Takala et al. (2009). According to the answers of the special class teachers and my teaching observations, teaching in small groups remains their main responsibility.

As the majority of special educators in Finland still belong to the profession of special class teacher (Ström \& Hannus-Gullmets, 2015) mainly occupied in special classes or special schools, one can assume that this picture has not changed significantly. The participants of this study see themselves as experts for children with mainly learning problems and behavioural challenges and prefer to be responsible for this specific group of students.

Respondents in this study indicated that they were better prepared to respond to the needs of children with disabilities due to their professional expertise.

These findings are not surprising as there are several studies in the current literature indicating that general education teachers do not feel prepared to work with students with special educational needs in their classrooms (Byrd \& Alexander, 2020; Page \& Davis, 2016; SimeCummins, 2015). As previous research has shown, it is important for general education teachers to possess a specific expertise and pedagogy to meet the diverse needs of these students in the inclusive classroom (Byrd \& Alexander, 2020, Dingle et al., 2004). This can be improved through improved teacher co-operation such as collaboration modules between general education and special education teachers (McKenzie, 2015)

Some participants (teacher 3,4 ) also consider it to be important to work with pupils with special needs in their own resource room, and not in mainstream education. Consequently, their 
pedagogical support for children with special needs has been organized in part-time and full-time special education placements.

The findings of the present study also reflect work done by Takala et al. (2015), who revealed that Finnish special education students expect they would more often work in segregated settings with small groups of children.

As pointed out by Malmqvist \& Nilholm (2016) the prevalence of segregated settings for children with special educational needs is almost impossible to reconcile with most understandings of inclusive education. A learning environment that is tailored to the needs of each individual child, however, has been mentioned as the most important factor for teaching students with special needs in small groups and not in the general classroom. Co-teaching and multiprofessional collaboration have been generally welcomed by the majority of the participants, however, these practices were not always part of the daily work of the participants presented in this study.

Recent studies from Finland (Ström \& Hannus-Gullmets, 2015) and internationally (Harvey et al., 2010) affirmed that universities are currently offering introductory courses in special education and inclusion-based practices to prospective teachers. However, in line with findings from current research (McKenzie, 2015; Sime-Cummins, 2015), the present study indicates, that there seems to be a lack of professional development programs in schools, that focus on inclusive practices such as collaborative planning.

The type and severity of students' disabilities have been identified as factors having an impact on the participants' attitudes towards teaching students with certain disabilities in the general education group. In addition, some of the participants regard the class and subject teacher's attitudes towards students with special needs and a lack of resources as main challenges in a possible cooperation. As previous research has shown, the type and severity of students' disabilities seem to have an important influence on teachers' attitude towards inclusion of students with certain disabilities in the mainstream classroom (Morley et al. 2005; Obrusnikova 2008). The lack of resources such as missing classroom support has also been identified as barriers to inclusive teaching practices in current studies (Harper, 2017; Saloviita, 2018; Takala et al., 2009).

\subsection{Limitations}

Several limitations from a methodological perspective apply to this study. First, the study was based on a limited sample of special educators and makes no claim for generalizability. The results may not be replicated if conducted as a large-scale study. More extensive data are required to confirm the findings of this study.

Moreover, this research focused only one group of teachers: Four special educators within inclusive settings were included in the study. Consequently, experiences from the perspective of only one professional group was portrayed. A focus on teachers working in mainstream schools was chosen to make the study more reliable and relevant.

Future research, however, should take into account the perspectives of different professionals to enrich the data. Finally, as the researcher was not familiar with the local language (Finnish), the interviews were conducted in English, which is not the native language for participants and researcher. During the data collection and analysis process, the language barrier became more significant. Interviewees had to describe their experiences in a foreign language (English) which may have influenced the depth and a breath of their responses.

\subsection{Perspectives}

The results of this study confirm the need for more effective cooperation between special educators and general education teachers. The frequency and quality of the collaboration between general educators and special educators could contribute to sharing knowledge about various teaching strategies to meet the needs of all students, including those with disabilities in practice. Inclusive practices such as co-teaching represent challenges to traditional conceptions of teaching and learning. As pointed out by Sirkko et al. (2018), "an open and honest interaction, open discussion 
of the possible personal differences and accepting the strengths and weaknesses of each teacher in the classroom seems necessary when co-teaching." School administrators should consider structural changes to the provision and organization of special support so that co-operation and co-teaching between different professionals can be easier planned and implemented. Therefore, the responsibility of all teachers, including class and subject teachers, to provide support for pupils with special needs should not only be emphasized in policy documents, but also on school level. The local policy environment should also support the realisation of the individual schools' inclusive values. As suggested by Dyson, Howes and Roberts (2002), schools should pay attention to the development of 'inclusive' cultures and establishing some degree of consensus around inclusive values in the school community.

Additionally, as suggested by Takala et al. (2015), further research on the different work profiles of special educators is required. More detailed case studies of individual schools in which the organization of support are investigated in more depth are needed (Magnússon et al., 2014). Future studies should also take into account the students' perspective of co-teaching and the organization of special support. Multiple case studies with observations and interviews with students and teachers could help to reveal a more detailed understanding of the everyday practice of the schools that are influenced by a) conceptual aspects and environmental conditions of schools such as the educational profile (Magnússon et al., 2014) and b) processes of inclusion and exclusion that are produced through daily interactions between the multi-professional staff and the students (e.g. Carrington \& Elkins, 2002).

\section{Declaration of Conflicting Interests}

The author declared no potential conflicts of interest with respect to the authorship and/or publication of this article.

\section{References}

Ainscow, M., Dyson, A., \& Weiner, S. (2013). From exclusion to inclusion: Ways of responding in schools to students with special educational needs. Manchester: CfBT Education Trust.

Alridge, J. (2008) 'What's happening in special education?' Childhood Education, 84(3),180-191

Bettini, E., Wang, J., Cumming, M., Kimerling, J., \& Schutz, S. (2019). Special educators' experiences of roles and responsibilities in self-contained classes for students with emotional/behavioral disorders. Remedial and Special Education, 40(3), 177-191.

Björn, P., Aaro, M. T., Koponen, T. K., Fuchs, L.S., \& Fuchs, D.H. (2016). The many faces of special education within RTI frameworks in the United States and Finland. Learning Disability Quarterly, 39(1), 58-66

Byrd, D. R. \& Alexander, M. (2020). Investigating special education teachers' knowledge and skills: Preparing general teacher preparation for professional development. Journal of Pedagogical Research. Advanced online publication. doi: 10.33902/JPR.2020059790

Carrington, S. (1999). Inclusion needs a different school culture. International Journal of Inclusive Education 3(3), 257-268

Carrington, S. \& Elkins, J. (2002). Comparison of a traditional and an inclusive secondary school culture. The International Journal of Inclusive Education 6(1), 1-16.

Dingle, M., Falvey, M.A., Givner, C. C., \& Haager, D. (2004). Essential special and general education teacher competencies for preparing teachers for inclusive settings. Issues in Teacher Education, 13(1), 35-50.

Dyson, A., Howes, A. \& Roberts, B. (2002). A systematic review of the effectiveness of school-level actions for promoting participation by all Students (EPPI-Centre Review, version 1.1). Research evidence in education library. London: EPPI-Centre, Social Science Research Unit, Institute of Education.

Pulkkinen, U., Linnanmäki, K. \& Aunio, P. (2015). Educational support for low-performing students in mathematics: the three-tier support model in Finnish lower secondary schools. European Journal of Special Needs Education 30(1), 75-92.

Ekstam, U., Linnanmäki, K. \& Aunio, P. (2015). Educational support for low-performing students in mathematics: the three-tier support model in Finnish lower secondary schools. European Journal of Special Needs Education 30(1), 75-92. 
Figg, C., Wenrick, M., Youker, C., Heilman, J., \& Schneider, C. (2010). Implications and benefits of a longterm peer debriefing experience on teacher researchers. Brock Education, 19(1), 20-35

Finnish National Board of Education (2016). National Core Curriculum for Basic Education 2014. National core curriculum for basic education intended for pupils in compulsory education. Helsinki: Finnish National Board of Education.

Flick, U. (2009). An introduction to qualitative research (4th ed.). London: Sage.

Hausstätter, R. \& Takala, M. (2008). The core of special teacher education: a comparison of Finland and Norway. European Journal of Special Needs Education, 23(2), 121-134.

Harper, D. L. (2017). The peripheral factors of inclusive education and teacher self-efficacy (Unpublished doctoral dissertation). Concordia University, the USA.

Harvey, M. W., Yssel, N., Bauserman, A. D. \& Merbler, J.B. (2010). Preservice teacher preparation for inclusion: An exploration of higher education teacher-training institutions. Remedial and Special Education, 31 (1), 24-33.

Jahnukainen, M. \& Itkonen, T. (2016). Tiered Intervention: History and Trends in Finland Compared with the Response to Intervention model (RTI) in the United States. European Journal of Special Needs Education, 31(1), 140-150.

Jahnukainen, M. \& Korhonen, A. (2003). Integration of Students with Severe and Profound Intellectual Disabilities into the Comprehensive School System: teachers' perceptions of the education reform in Finland. International Journal of Disability, Development and Education, 50(2), 169-180.

Lüders, C. (2009). Beobachten im Feld und Ethnographie. In U. Flick, E. von Kardoff and I. Steinke (Eds.) Qualitative Forschung. Ein Handbuch, (pp. 384-402). Reinbek: Rohwolt

Magnússon, G., Göransson, K., \& Nilholm, C. (2015). Similar situations? Special needs in different groups of independent schools. Scandinavian Journal of Educational Research, 59(4), 377-394.

Malinen, O.-P., Vaisanen, P., \& Savolainen, H. (2012). Teacher Education in Finland: A Review of a National Effort for Preparing Teachers for the Future. The Curriculum Journal, 23, 567-584. http://dx.doi.org/10.1080/09585176.2012.731011

Malmqvist, J. \& Nilholm, C. (2016). The antithesis of inclusion? The emergence and functioning of ADHD special education classes in the Swedish school system. Emotional and Behavioural Difficulties, 21(3), 287300.

Mayring, P. (2010). Qualitative inhaltsanalyse: Grundlagen und techniken (11th ed). Weinheim: Beltz.

McKenzie, R. J. (2015). Perceptions of inclusion factors by general education teachers and administrators (Unpublished Doctoral dissertation). Walden University, the USA.

Meho, L. (2006). E-mail interviewing in qualitative research: A methodological discussion. Journal of the American Society for Information Science and Technology, 57(10), 1284-1295.

Morley, D., Bailey, R., Tan, J., \& Cooke, B. (2005). Inclusive physical education: teachers' views of including pupils with special educational needs and/or disabilities in physical education. European Physical Education Review, 11(1), 84-107.

Munk, M., \& Agergaard, S. (2015). The processes of inclusion and exclusion in physical education: A socialrelational perspective. Social Inclusion, 3(3), 67-81.

Obrusnikova, I. (2008). Physical educators' beliefs about teaching children with disabilities. Perceptual and Motor Skills, 106(2), 637-644.

Official Statistics of Finland [OSF] (2019a). Appendix table 1. Comprehensive school pupils having received intensified or special support, 2018. Helsinki: Statistics Finland.

Official Statistics of Finland [OSF] (2019b). Appendix table 5. Comprehensive school pupils having received special support by place of provision of teaching, 2018. Helsinki: Statistics Finland.

Page, A., \& Davis, A. (2016). The alignment of innovative learning environments and inclusive education: How effective is the new learning environment in meeting the needs of special education learners? New Zealand Journal of Teachers' Work, 13(2), 81-98.

Patton, M. Q. (2002). Qualitative research and evaluation methods (3rd ed.). Thousand Oaks, CA: Sage.

Pirttimaa, R., T. Kokko, L. Räty, H. Pesonen, \& Ojala, T. (2015). Intensive special educational needs and the development of inclusive practices in Finland. In F. Dovigo, C. Favella, F. Gasparini, A. Pietrocarlo, V. Rosso \& E. Zappell (Eds.) Special Education Needs and Inclusive practices: An International Perspective (pp. 149-153). Bergamo: University of Bergamo.

Pulkkinen, J. \& Jahnukainen, M. (2016). Finnish reform of the funding and provision of special education: the views of principals and municipal education administrators. Educational Review, 68(2), 171-188. 
Saloviita, T. (2018). Attitudes of teachers towards inclusive education in Finland. Scandinavian Journal of Educational Research, 64(2), 270-282

Savolainen, H., Engelbrecht, P., Nel, M. \& Malinen, O.-P. (2012). Understanding teachers' attitudes and selfefficacy in inclusive education: Implications for pre-service and inservice teacher education. European Journal of Special Needs Education, 27(1), 51-68.

Sirkko, R., Takala, M. \& Wickman, K. (2018). Co-teaching in northern rural Finnish schools. Education in the North, 25(1-2), 217-237.

Sime-Cummins, P. (2015). Perceived self-efficacy of secondary general education teachers in the inclusive classroom (Unpublished Doctoral dissertation). Walden University, the USA.

Ström, K. \& Hannus-Gullmets, B. (2015). From special (class) teacher to special educator: The Finnish case. In D. L. Cameron and R. Thygesen (Eds.) Transitions in the field of special education: Theoretical perspectives and implications for practice (pp. 137-150). Münster: Waxmann.

Sundqvist, C., Björk-Åman, C. \& Ström, K. (2019). The three-tiered support system and the special education teachers' role in Swedish-speaking schools in Finland. European Journal of Special Needs Education, 34(5), 601-616.

Takala, M., \& Head, G. (2017). Inclusion and practice: The perspective of two countries. In M. T. Hughes, \& E. Talbott (Eds.), The handbook of diversity in special education (pp. 115-128). Chichester: John Wiley Press. doi: 10.1002/9781118768778

Takala, M., Pirttimaa, R. \& Törmänen, M. (2009). Inclusive special education: The role of special education teachers in Finland. British Journal of Special Education, 36(3), 162-172

Takala, M., Wickman, K., Uusitalo-Malmivaara, L. \& Lundström, A. (2015). Becoming a special educator Finnish and Swedish students' views on their future professions. Education Inquiry, 6(1), 25-51.

Tracy, S. J. (2010). Qualitative quality: Eight "Big-Tent" criteria for excellent qualitative research. Qualitative Inquiry, 16(10), 837-851.

UNESCO (1994). The Salamanca Statement and Framework for Action on Special Needs Education. Adopted by the World Conference on Special Needs Education: Access and Quality, Salamanca, Spain, 7-10 June 1994. Paris: UNESCO

United Nations. (2006). Convention on the rights of persons with disabilities and optional protocol. Retrieved from: http://www.un.org/disabilities/documents/convention/ convoptprot e.pdf

Vislie, L. (2003). From integration to inclusion: focusing global trends and changes in the western European societies. European Journal of Special Needs Education, 18(1), 17-35

Wolgast, A. \& Fischer, N.(2017). You are not alone: Colleague support and goal-oriented cooperation as resources to reduce teachers' stress. Social Psychology of Education: An International Journal, 20(1), 97-114. 